\title{
AMBIENT OZONE AND BACTERIUM STREPTOCOCCUS: A LINK BETWEEN CELLULITIS AND PHARYNGITIS
}

\section{GIUSEPPE VALACCHI ${ }^{1,2}$, EUGENIUSZ PORADA ${ }^{3}$, and BRIAN H. ROWE ${ }^{4}$}

${ }^{1}$ University of Ferrara, Ferrara, Italy

Department of Life Sciences and Biotechnology

${ }^{2}$ Kyung Hee University, Seoul, South Korea

Department of Food and Nutrition

${ }^{3}$ Universite du Quebec en Outaouais, Quebec, Canada

Computer Science Department (Professor Emeritus)

${ }^{4}$ University of Alberta, Edmonton, Alberta, Canada

School of Public Health, Department of Emergency Medicine

\begin{abstract}
Objectives: Ambient air pollution, as many publications indicate, may have associations with skin condition. The aim of this study has been to examine such common relations for cellulitis and pharyngitis. The hypothesis is that ambient ground-level ozone may help bacteria to penetrate skin or throat. Material and Methods: We used the emergency department (ED) visits data in Edmonton, Canada for the period from 1992 (April) to 2002 (March). We retrieved all the diagnosed ED visits for cellulitis and pharyngitis. Case-crossover design was used to study potential association between ozone and those visits. Conditional logistic regression was used to estimate odds ratios (OR) and their $95 \%$ confidence intervals (95\% CI). Results: The results are reported for the interquartile range $(\mathrm{IQR}=17.9 \mathrm{ppb})$ for $8 \mathrm{~h}$ maximum ozone. Positive and statistical significant results were obtained as follows: for lags from 0 to 3 (OR = 1.07, 95\% CI: 1.03-1.12, lag 2); for lags from 0 to 6 days $(\mathrm{OR}=1.08,95 \% \mathrm{CI}$ : 1.03-1.12, lag 3); for lags from 0 to 4 (OR = 1.06, 95\% CI: 1.03-1.09, for lag 2 and 3 ). Conclusions: The findings suggest the response to exposure to ambient ground-level ozone for skin and pharyngitis considered separately and jointly.
\end{abstract}

Key words:

Inflammation, Air pollution, Ozone, Cellulitis, Bacteria, Pharyngitis

\section{INTRODUCTION}

Short-term exposure to ambient ozone $\left(\mathrm{O}_{3}\right)$ has been associated with various skin conditions [1-3], including cellulitis $[4,5]$. Two of the most common bacteria responsible for cellulitis are Staphylococcus and Streptococcus species. Streptococcus species also infect other body systems such as the respiratory tract, including the throat and lungs.

In this study, we conducted a case-crossover analysis [6] to evaluate the potential association between the emergency department (ED) visits for cellulitis or/and pharyngitis and ambient ozone exposure. We based our

Received: March 24, 2014. Accepted: November 21, 2014.

Corresponding author: G. Valacchi, University of Ferrara, Department of Life Sciences and Biotechnology, Via Borsari 46, 44121 Ferrara (FE), Italy (e-mail: vlcgpp@unife.it). 
study on the known impact of ozone on skin [7-9] or epithelial barriers [10], where ambient ozone can cause susceptibility to viral or bacterial infections. We assumed that similar effects of ozone should be observed for both diseases.

\section{MATERIAL AND METHODS}

We retrieved data on the ED visits for cellulitis and pharyngitis between April 1992 and March 2002 from 5 hospitals in Edmonton, Canada. Out of all the diagnosed ED visits for cellulitis $(\mathrm{N}=69547)$ we chose the cases identified on uncovered parts of body [4]. This restriction resulted in 27101 cases used in our analysis. Out of all the diagnosed ED visits for upper respiratory disease $(\mathrm{N}=133288)$ we identified 24078 ED visits for pharyngitis.

We represented the daily exposure to ambient ozone as its 8-h daily maximum (3652 values of the mean $(\mathrm{M})=28.2 \mathrm{ppb}$ and standard deviation $(\mathrm{SD})=12.4 \mathrm{ppb})$. We applied the time-stratified version of the case-crossover design to define control periods for the case period. We used SAS EG version 4.2 software (PHREG procedure) to estimate odds ratios (OR) and their $95 \%$ confidence intervals $(\mathrm{CI})$. The results are reported for the increase in exposure represented by the interquartile range $(\mathrm{IQR}=17.9 \mathrm{ppb})$. Temperature and relative humidity were adjusted in the form of natural splines for the purpose of the models.

\section{RESULTS}

In the case of cellulitis we obtained the following results for the lags from 0 to 6 : OR $=1.04$ (95\% CI: $1.01-1.08$ ), $\mathrm{OR}=1.05$ (95\% CI: $1.01-1.09), \mathrm{OR}=1.07(95 \% \mathrm{CI}: 1.03-$ 1.12), OR $=1.04$ (95\% CI: $1.00-1.08), \mathrm{OR}=1.02(95 \% \mathrm{CI}$ : $0.98-1.05)$, OR $=0.98$ (95\% CI: $0.95-1.02)$, OR $=0.98$ (95\% CI: 0.95-1.02), respectively.

For pharyngitis the corresponding results were as follows: $\mathrm{OR}=1.06$ (95\% CI: $1.02-1.11), \mathrm{OR}=1.06$ (95\% CI:
$1.02-1.11), \mathrm{OR}=1.05$ (95\% CI: 1.01-1.09), OR = 1.08 (95\% CI: $1.03-1.12)$, OR = 1.06 (95\% CI: $1.02-1.11)$, OR $=1.06$ (95\% CI: $1.02-1.10)$, OR $=1.04(95 \%$ CI: $1.00-1.08)$, respectively.

As we assumed that ozone facilitates bacterial invasion (skin or throat), we analyzed both health conditions together $(\mathrm{N}=51$ 179). For both conditions we obtained: OR $=1.05$ (95\% CI: $1.02-1.08)$, OR $=1.05$ (95\% CI: $1.02-$ $1.08), \mathrm{OR}=1.06(95 \% \mathrm{CI}: 1.03-1.09), \mathrm{OR}=1.06(95 \% \mathrm{CI}$ : $1.03-1.09)$, OR $=1.04$ (95\% CI: $1.01-1.07)$, OR $=1.02$ (95\% CI: 0.99-1.05), OR = 1.01 (95\% CI: 0.98-1.04), respectively. As far as these results are concerned, the bold indicates positive and statistically significant $(p<0.05)$ associations.

Additionally, we performed the time-series analysis with distributed lags under non-linear models (the package dlnm in $\mathrm{R}$ 2.15.2). In this situation we analyzed daily counts of the ED visits. The Figure 1 shows the results for cellulitis; the estimated relative risk (RR and 95\% CI) along the lags for 1 unit increase.

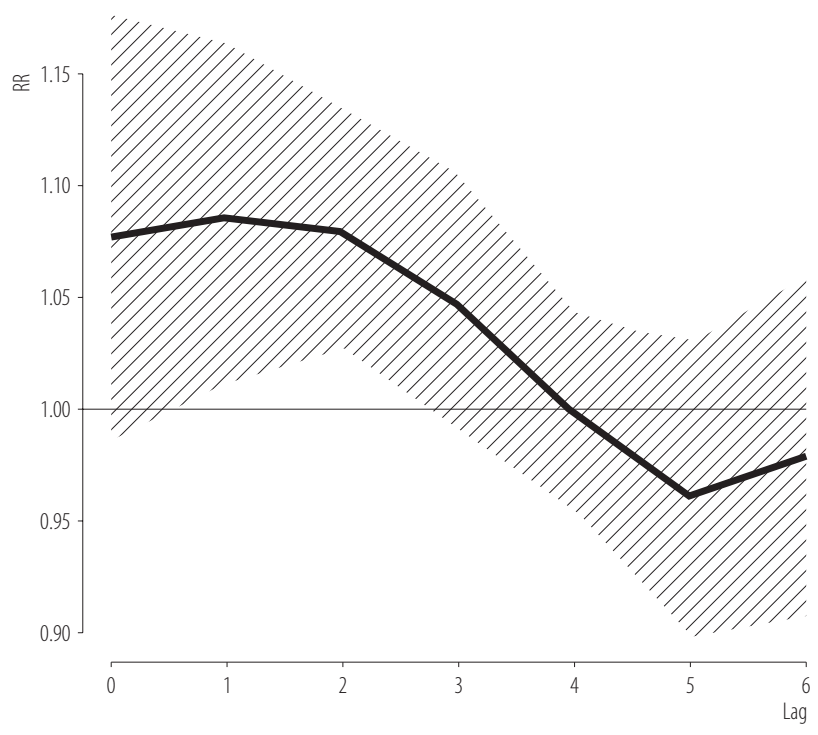

The estimated relative risks (RR) and their corresponding 95\% confidence intervals are shown.

Fig. 1. Effects of 1 unit increase in ozone along lags estimated for emergency department visits for cellulitis 


\section{LIMITATIONS}

There are several limitations of this study that require to be elaborated upon. They include the adequacy of the model and impact of measurement error in the exposure and outcome variables. The fixed-site monitoring sites available in Edmonton provide daily pollution exposures of ambient air pollution and are applied to represent average population exposure. The fixed site monitors do not fully reflect variation in exposure among individuals; however, alternatives are not readily available. The individual data on potentially important effect modifiers such as medication use, smoking status, socio-economic status, race and other medical co-morbidities have not been available from this database. We have conducted numerous hypothesis tests, increasing the risk of false positive results; however, we have observed trends or similar statistical results for different health conditions categorized as lower respiratory conditions.

Many episodes of cellulitis and pharangitis do not result in an ED visit, thus our findings are not generalizable to all such episodes. This data would, however, reflect the more severe or symptomatic cases as well as cases that become symptomatic when other health services are unavailable. It is possible that high ozone levels are correlated with sunny weather, when persons spend more time outside, and consequently other environmental factors may also influence health; however, the majority of the presentations were in the winter months.

Ground level ozone is formed when nitrogen dioxide $\left(\mathrm{NO}_{2}\right)$ is exposed to the ultraviolet radiation in sunlight. Organic gas concentrations in the atmosphere have a significant effect on ozone levels. The large majority of this air pollution arises from combustion of fossil fuels (e.g., automobile sources of air pollution). It is reasonable to assume that lower respiratory tract presentations would be highest during peak combustion of fossil fuels and that interventions to reduce fossil fuel combustion may have direct influence on health care resource use. Ground-level ozone is a secondary pollutant and may actually be scavenged from the air by fresh combustion pollutants.

\section{CONCLUSIONS}

Our epidemiological analysis reinforces knowledge arising from in vitro and in vivo studies regarding the detrimental effects of ozone on skin and mucous membranes.

\section{ACKNOWLEDGMENTS}

The authors appreciate the efforts of the AHS-Edmonton Zone, especially Virginia Willis and Chris Huston, for securing this data. The authors acknowledge Environment Canada for providing the air pollution data from the National Air Pollution Surveillance (NAPS) network that was used in this study. The authors thank Dr. Mieczyslaw Szyszkowicz for the helpful discussion and suggestions for revisions. Dr. Rowe's research is supported by a Tier I Canada Research Chair in the Evidencebased Emergency Medicine from the Canadian Institutes of Health Research (CIHR) through the Government of Canada (Ottawa, Ontario).

\section{REFERENCES}

1. Larrieu S, Lefranc A, Gault G, Chatignoux E, Couvy F, Jouves B, et al. Are the short-term effects of air pollution restricted to cardiorespiratory diseases? Am J Epidemiol. 2009;169:1201-8, http://dx.doi.org/10.1093/aje/kwp032.

2. Szyszkowicz M, Porada E, Searles G, Rowe B. Ambient ozone and emergency department visits for skin conditions. Air Qual Atmos Health. 2012;5:303-9, http://dx.doi.org/10. 1007/s11869-010-0092-5.

3. Xu F, Yan S, Wu M, Li F, Xu X, Song W, et al. Ambient ozone pollution as a risk factor for skin disorders. Br J Dermatol. 2011;165:224-5, http://dx.doi.org/10.1111/j.1365-2133. 2011.10349.x.

4. Szyszkowicz M, Porada E, Kaplan G, Rowe B. Ambient ozone and emergency department visits for cellulitis. Int J Environ Res Public Health. 2010;7:4078-88, http://dx.doi.org/10.3390/ ijerph7114078. 
5. Szyszkowicz M, Porada E, Grafstein E, Kaplan G. Ambient ozone as a risk factor for ED visits for cellulitis. Environ Pollut. 2012;1(2):105-11, http://dx.doi.org/10.5539/ep.v1n2p105.

6. Maclure M. The case-crossover design: A method for studying transient effects on the risk of acute events. Am J Epidemiol. 1991;133:144-53.

7. Valacchi G, van der Vliet A, Schock BC, Okamoto T, Obermuller-Jevic U, Cross CE, et al. Ozone exposure activates oxidative stress responses in murine skin. Toxicology. 2002;179:163-70, http://dx.doi.org/10.1016/S0300-483X (02)00240-8.
8. Valacchi G, Fortino V, Bocci V. The dual action of ozone on the skin. Br J Dermatol. 2005;153:1096-100, http:// dx.doi.org/10.1111/j.1365-2133.2005.06939.x.

9. Valacchi G, Sticozzi C, Pecorelli A, Cervellati F, Cervellati C, Maioli E. Cutaneous responses to environmental stressors. Ann N Y Acad Sci. 2012;1271:75-81, http:// dx.doi.org/10.1111/j.1749-6632.2012.06724.x.

10. Hollingwhorst JW, Kleeberger SR, Forster MW. Ozone and pulmonary innate immunity. Proc Am Thorac Soc. 2007;4:240-6, http://dx.doi.org/10.1513/pats.200701-023AW.

This work is available in Open Access model and licensed under a Creative Commons Attribution-NonCommercial 3.0 Poland License - http://creativecommons.org/ licenses/by-nc/3.0/pl/deed.en. 